\title{
An Evaluation of the Examination Assessment Techniques used by the Zimbabwe School Examinations Council (ZIMSEC) for grade 7 Deaf Candidates (PART B.)
}

\author{
Lincoln Hlatywayo ${ }^{1}$, Alfred, C. Ncube $(\mathrm{PhD})^{2}$, Fredrick Mwale ${ }^{3}$ \\ Senior Lecturer: Disability Studies and Special Needs Education, Zimbabwe Open University \\ Acting Pro-Vice Chancellor (Academic): Zimbabwe Open University \\ Examinations Manager (Special Needs) ZIMSEC
}

\begin{abstract}
The study evaluated the examination assessment techniques used by ZIMSEC at grade 7 level. The study was motivated by the low pass rate among deaf candidates at grade 7 level in the period 2007 to 2011. At the centre of the study were two variables namely exam item development and exam paper administration. The descriptive survey design was used to solicit data from Zimbabwe School Examinations Council officials, teachers of candidates with profound hearing impairment and from heads of special schools that enroll students with hearing impairment. The population under study comprised 101 teachers of students with profound hearing impairment in the five special schools in Zimbabwe, 4 heads of special schools that enroll students with profound hearing impairment and about 300 officials from the Zimbabwe School Examinations Council. Nonprobability sampling methods were used to come up with a representative sample of 4 school heads, 50 teachers and 10 Examination Managers. The results showed that the assessment language (English) was a great barrier to the deaf candidates as questions were asked in their abstract form. There was also concern raised where sign language differences could affect interpretation of examinations. More importantly the results revealed that teachers of the deaf were not involved in the marking process and the majority was not aware of how the exam scripts are marked or the availability of an assessment policy. Lastly the grading system used did not have some special provisions for the deaf candidates. The study recommended that the Zimbabwe School Examinations should establish flexible formats for candidates with profound hearing impairment to be able to present their responses. These formats should include signing on videos and responding in sign language to an amanuensis/ transcriber. The Government and stakeholder should establish a sign language authority to unify in language, train teachers of the deaf in sign language, interpretation ethics and license sign language interpreters. Zimbabwe School Examinations Council should establish guidelines that are specific to the marking scripts for candidates with profound Hearing Impairment. The government should establish and enforce a policy on the assessment of candidates with hearing impairments. It was also recommended that the Curriculum Development Unit should establish a sign language syllabus to allow candidates with hearing impairment to be assessed for proficiency in their primary language instead of proficiency in English and local languages.
\end{abstract}

Key terms: Measurement: Deafness, Special School, Hearing impairment, Assessment procedures Examination Accommodation, Special arrangements

\section{Introduction and Background}

The teaching, learning and assessment of students with profound hearing impairment in special schools, resource units and full inclusive settings have been met with challenges of highest degree in Zimbabwe. The fact that students with profound hearing impairment are subjected to the same educational milestones and the same examinations with those of their mainstream counterparts seem to weigh down on the former. Like their mainstream counterparts, students with profound deafness need feedback, they need to be motivated to learn and they have aspirations which are hinged on results of teaching, learning and assessment. They also need to boost their self esteem through performing to their optimal capacity, but this often is met with disappointments.

At grade seven, students with absolute deafness write end of course examinations in subjects like English, Shona/ Ndebele/Tonga/Nambia, Mathematics and General Paper and results revealed that they faced various challenges despite that they are taught by specialist teachers and are accorded an opportunity to do the course in more years than the seven years their mainstream counterparts are confined to. The predicament students with profound hearing impairment are in seemed to have worsened with the introduction of assessment through structured and essay components by the Zimbabwe School Examinations Council in 2002, raising issues of curriculum and assessment procedure appropriateness as well as human resource competence in schools that enroll students with profound hearing impairment. 
The trend was that special schools for the students with hearing impairment were ranked among the least performers academically each year on the Provincial Education Directors' Merit Awards throughout the country's nine provinces. Some special schools for students with profound hearing impairment registering zero percent pass rate every year. Observations revealed that some resource units in mainstream schools have since closed because Heads of such schools were considering enrolling students with profound hearing impairment a threat to their highly esteemed pass rates.

Statistics collected from the Zimbabwe School Examinations Council (ZIMSEC) confirmed the dismal performance by candidates with deafness in Zimbabwe's special schools for students with deafness over five years. The gifted students with hearing impairment, who pass grade seven, have been observed to perform below their expected threshold. Very few students with profound hearing impairment have been recorded to have passed with distinctions and the question is: were all students with hearing impairment in schools average and below average learners? Are there no gifted or exceptionally intelligent students among those with profound hearing impairment?

The statistics captured below include candidates with residual hearing and those with normal hearing in reverse inclusion. Thus the actual pass rates for candidates with severe to profound deafness can even be lower than is reflected below.

Table 1: Grade 7 Pass Rate of Deaf Candidates: 2007-2011

\begin{tabular}{|l|c|c|c|}
\hline Year & Total Candidature & Number Passed & Percentage \\
\hline 2007 & 59 & 22 & 37.3 \\
\hline 2008 & 48 & 9 & 18.75 \\
\hline 2009 & 41 & 8 & 19.51 \\
\hline 2010 & 68 & 17 & 25 \\
\hline 2011 & 60 & 12 & 20 \\
\hline
\end{tabular}

(Statistics compiled from ZIMSEC records, 2012)

If the candidates in institutions were this affected when they have more resources, more qualified and more experienced personnel than those in resource units, one wonders what it is like to similar students in the mainstream school settings.

The researchers also noted with regret the dropout rate of students with absolute deafness. The majority of these students have failed to proceed to secondary school and are street vending. They are seen at places like Harare's popular Copper Cabana. A comparative analysis between the number of candidates who register for grade seven and those who register for Ordinary level has made alarming revelations on dropout cases soon after grade seven. An average of 100 candidates with deafness is registered for grade seven against an average of 20 candidates registered for Ordinary level each year and not even one has been recorded to have completed Advanced level. The disparity is regrettable. This is adequate proof that candidates give up on education soon after their first national summative examination.

It is against this background that the researchers deemed it necessary to conduct a research that establish the factors surrounding assessment procedures used by ZIMSEC that impact on performance measurement of candidates with profound hearing impairment.

\subsection{Statement of the Problem}

There has been a high failure rate observed over the years among candidates with absolute deafness at grade seven levels. This has consequently led to high dropout rate by students with profound deafness soon after grade seven. Parents, teachers and administrators of deaf students have questioned the relevance and validity of assessment procedures Zimbabwe School Examinations Council is using to benchmark standards for these candidates. The research sought to answer the question: What factors impact on performance measurement of candidates with hearing impairment at grade seven level?

\subsection{Sub-Problems}

- How does the actual marking of examinations scripts affect performance measurement for candidates with profound hearing impairment?

- What are the effects of the language used in assessment instruments on the performance of candidates with profound hearing impairment?

\subsection{Delimitation of the Study}

The research study sought to solicit data on assessment procedures for candidates with profound hearing impairment from the Zimbabwe School Examinations Council. The focus was also on special schools that enroll students with profound hearing impairment such as Emerald Hill in Harare, Jairos Jiri Naran Centre 
in Gweru, King George VI in Bulawayo and Henry Murray schools for the deaf in Masvingo as a follow up on the implementation of the procedures and impact assessment.

\section{Conceptual Framework}

Assessment practices in education vary and are dependent on diverse theoretical frameworks of practitioners and researchers, their assumptions and beliefs about the nature of human mind, the origin of knowledge and the learning process of the target group (Earl, 2003). In this research the conceptual framework was influenced by the Marxist's conflict theory and the social model of disability which gave birth to disability rights movement. The disability rights movement contributed to an understanding of people with disabilities as a minority or a coalition of minorities who are disadvantaged by society, not just as people who are disadvantaged by their impairments. Teaching strategies that are disabling and unfair assessment procedures impact negatively on the performance measurement of children with hearing impairment. Advocates of disability rights emphasise differences in physical or psychological functioning, rather than inferiority. Feagin (1984) states that a minority group has five characteristics which are:

(1) Suffering discrimination and subordination, (2) physical and/ or cultural traits that set them apart, and which are disapproved by the dominant group, (3) a shared sense of collective identity and common burdens, (4) socially shared rules about who belongs and who does not determine minority status, and (5) tendency to marry within the group. The Deaf Community fits well in the enshrined characteristics and is often regarded as a linguistic and cultural minority rather than a group with disabilities, and some Deaf people do not see themselves as having a disability at all. (The Convention on the Rights of Persons with Disabilities, 2006).

Candidates with profound hearing impairment are disadvantaged by assessment procedures that are designed to cater for the dominant group. This framework has led to a ranging controversy over assessment issues like efficacy and adequacy of public examinations and bias against minority and marginalized groupsthose with profound hearing impairment included (Kofitse, 2010). Dietel, Herman and Knuth (1991) observed that while assessment has the potential to improve learning of all students, historically it has acted as a barrier rather than a bridge to educational opportunities. Assessment systems have attracted severe criticisms for their perceived imperfections in measuring student achievement. Questions of bias, unfairness and inequities among others are raised about examinations. Increasing diversity of societies among other factors has increased the need to offer equal opportunities for all, fairness in assessment and selection processes (Kofitse, 2010). Sedlacek and Kim (1995) argued that although many of the measures most widely used have established validity and reliability, in some instances, these measures are often used inappropriately and unethically with populations from different cultures. If people have different cultural experiences and (this includes people with deafness) present their abilities differently, it is unlikely that a single measure could be developed that would work equally for all (Kofitse, 2010). Scholars therefore are calling for democratizing assessment.

Assessment and examination policies, practices and procedures should provide disabled students with the same opportunity as their peers to demonstrate the achievement of learning outcomes (QAA Code of Practice- Precept 13, 1999).

For assessment to be effective and valid, it must be able to assess the aims of the course, provide sufficient evidence to enable professional judgment of the learner, support the teaching and learning strategies and for the integral part of the scheme (Agbo and Mankilik, 1999). The setting, moderation and administration of a fair and equitable examination for Deaf students, remains a challenge for Examinations Bodies, teaching specialists have noted. The research on the evaluation of Zimbabwe School Examinations Council's assessment procedures to determine performance measurement for candidates with profound deafness was based on this conflict theory. Access, equity and fairness were key attributes underlying this research.

\section{Marking Scripts for Candidates With Deafness}

Questions of fairness arise not only in the selection of performance tasks but in the scoring of responses. Educational Testing Service (2009) postulated that when people use test scores, they make influences about the knowledge, skills or other attributes of test takers on the basis of the scores.. The extent to which those inferences are appropriate is an important aspect of validity and the extent to which those inferences are appropriate for different groups of test takers is an important aspect of fairness. This encourages a standardized and consistent way of scoring for candidates with deafness. Speaking in an interview with the Nimo, (2012) a teacher at the Koforidua Unit School for the Deaf, having noticed the challenges and unfair practices faced by candidates with deafness during marking suggested that the WAEC could alternatively decide to use a different marking scheme for the deaf students if the Council felt that the current mode of examinations should not be altered. He argued that the use of telegraphic language that is employed in tutoring the deaf was not premised on modern English grammar and syntax, thereby putting such students at a disadvantage. 
At Stiggins (1991) has stated, it is critical that the scoring procedures are designed to assure that 'performance ratings reflect the examinee's true abilities and are not a function of the perceptions and biases of the persons evaluating the performance'. The same could be said regarding the perceptions and biases of the persons creating the test. The training and calibrating of raters is critical in this regard" The raters should be those people with experience with, have psychology of and understand the language of candidates with deafness. Guideline for Marker of Deaf Students (2007) hinted that examiners are not expected to compensate students by giving them additional marks because of their disability. They are expected to use discretion by making reasonable adjustments to the marking process given the English language difficulties encountered by hearing impaired students, in accordance with the Disability Discrimination Act 2005. The means of awarding marks should reflect the student understands of the subject rather than the level of their linguistic skills and wherever possible, the mark recorded for the piece of work should be the mark awarded on the basis of the content.

Observations made by specialist in the education of the deaf are that a student who is Deaf or Hard of Hearing can be disadvantaged when assessment takes the form of a written times examination (Exam Policy, Trinity College of Dublin, 2008). Raters or examiners should note that the student's written work may contain surface errors in spelling and grammar such as inaccuracies in the use of tense, grammatical agreement, plurals, spelling and punctuation, structural flaws including weak sequencing of ideas, paragraphs, and sentences; unclear expression of cause and effect; lack of competence in using abstract language or lack of awareness of writing genre.

UClan Statement Assessment Procedures and BSL (2012) prescribed about nine marking guidelines to be considered when marking the examination script of a student who is Deaf or Hard of Hearing, as enshrined below:

- First, read the script quickly to judge the student's underlying understanding of the topic; then assess their performance against the learning outcomes. If the script contains all the required elements but does not introduce them in a clear logical order, avoid penalizing the student for a lack of structure in their writing unless this is a stipulated competency being assessed.

- Errors in spelling do not mean that the student is confused about the meaning of the word or its function in their writing. Generally, such errors do not lead to ambiguity and should not be penalized when subject knowledge is being assessed.

- Lexical errors, such as coarse for course, do not mean that the student is confused about the meaning of the words. This kind of error should not be penalized unless it leads to ambiguity.

- Grammatical errors, like incorrect tense endings, lack of subject- verb agreement and incorrect word order may not affect the meaning of the sentence. Here the student's meaning is clear, the errors do not lead to ambiguity and the student should not be penalized.

- Punctuation may not be used as a tool for clarifying meaning. Scripts may long sentences that are difficult to follow with indiscriminate punctuation or no punctuation at all. Very short sentences or fragments of sentences might also be produced. For instance: The study considered three main areas of research. The effects of frequent drug use the role of the family in the offenders' behavior and the impact of custodial sentences on reoffending. In this case the student's meaning is clear, but such errors can lead to ambiguity which will be reflected in the mark awarded.

- Some students may have restricted vocabulary and use a far more limited range of words that one would respect. Avoid penalizing students who may have an immature style of writing, unless written communication is a specified learning outcome.

- Where grammar and spelling are core competencies of a course a student's work must be marked on the basis of accuracy in the language and therefore these marking guidelines will not apply.

- In all subjects, if a student's errors make a material difference to the meaning of their work, it will not be possible to clarify them as surface errors that do not incur penalty. For instance, if a nursing student writes hypertension instead of hypotension, this will affect the mark awarded.

The focus of this research study was to find out if such points given above underlie the marking of scripts for candidates with deafness at ZIMSEC and if not are there alternative procedures and what effect do they have on the performance measurement of candidates profound hearing impairment.

It should be noted that evaluation should be on the basis of achievement of explicitly stated learning outcomes, and nothing said above should be taken to override that. In particular, where accuracy of written expression needs to be demonstrated under time constraints or without supporting technologies, errors should not be discounted. An Examinations Board of Studies should indicate where this is the case. Where the writing does not make sense and it is not clear that the student has demonstrated the knowledge required, you are not expected to re-interpret what the student has written. Marking guides apply to timed examinations only. 
Exam Policy, Trinity College Dublin (2008) prescribed to those who mark examinations for candidates with hearing impairment if possible, to mark the work using two different coloured pens: one for comments about the material and the use of ideas, the other for comments about spelling, grammar, organization of material, linguistic expression and other aspects that have to do with the candidate's communication skills. If using this recommendation, please state which colour represents comments on ideas and which one represents errors in communication skills. This researcher observes that while the prescription is ideal in formative assessment, it may not be helpful in summative assessment since the candidates will not have assessment, it may not be helpful in summative assessment since the candidates will not have access to the scripts when they are marked.

\section{Methodology}

The descriptive survey design was used to solicit data from Zimbabwe School Examinations Council officials, teachers of candidates with profound hearing impairment and from heads of special schools that enroll students with hearing impairment. The design was critical in describing the assessment procedures available at ZIMSEC, explain their appropriateness in measuring performance of candidates with profound hearing impairment, suggesting improvements and predicting the effects of these improvements. Ithe descriptive survey design is considered apt because it gives the researchers the leverage to gather, organize, describe and analyse data in a very flexible way (Okonkwo-Uwandulu, Ojo and Onoja, 2012). The flexibility was visible in concurrent triangulation design (Cresswell, 2003) where qualitative and quantitative strategies were applied simultaneously to observe the same phenomenon. Questionnaires to teachers of students with hearing impairment and to ZIMSEC officials comprised the quantities strategy. Qualitative strategies involved interviews with heads of schools that enroll students with profound hearing impairment and focus group discussions with teachers of students with profound hearing impairment.

The population under study comprised 101 teachers of students with profound hearing impairment in the five special schools in Zimbabwe, 4 heads of special schools that enroll students with profound hearing impairment and about 300 officials from the Zimbabwe School Examinations Council. The common traits in the population were that they all were individual members who worked towards performance measurement of candidates with deafness.

Convenient sampling was done to target special schools for students with deafness and their heads since there are only five special schools in the country. Simple random sampling was employed to select teachers of students with profound hearing impairment. The sample required fifty teachers from the 101 teachers in five especial schools. All the 5 heads of special schools were obtained as a sample. Purposive sampling was done to come up with the ten officials from ZIMSEC. It was critical to target only those officials who were subject managers of the five subjects (Mathematics, General Paper, English, Shona and Ndebele) candidates with profound hearing impairment sit for at grade seven level and the regional managers who deal with the respective special schools during test administration. The researchers strongly ensured the sample contained the properties and parameters of the represented population. Inferential statistics was used to determine the whole population of officials who dealt with candidates with profound hearing impairment at every assessment procedure affecting performance measurement of candidates with profound hearing impairment.

A questionnaire was designed as a research instrument for gathering data from both the teachers of children with profound hearing impairment and ZIMSEC subject and regional managers. The questionnaire had a section for demographic data only that influenced the trend of responses. The questionnaire also was divided into themes as influenced by the sub-problems in chapter one. The researchers employed the use of an interview with heads of the four special schools that enroll students with profound hearing impairment. The interview schedule was designed to augment data collected from the use of questionnaires. The interviews were structured in a way that satisfied the themes developed from research sub-problems. The same questions in the interview schedule to the heads of schools that enroll students with hearing impairment were also used in a focus group discussion with teachers of candidates with profound hearing impairment. The role of the researchers was to just direct and redirect the discussion and every participant was kept focused throughout the discussion.

The researchers carried out a pilot study at St. Giles Primary School in Harare District in Zimbabwe to assess the reliability and validity of the research instruments. Pilot testing was administered to five teachers of children with profound hearing impairment and the head of the school. Other subject managers at ZIMSEC which were not part of the cohort formed part of the respondents to the pilot study. From the participants, the researchers realized that the items on both the questionnaires to teachers of students with profound hearing impairment needed to probe and find out what teachers of students with profound hearing impairment needed to probe and find out what teachers and managers thought about the assessment procedures available not to just say they agreed or disagreed. It was realized that room for opinions like 'strongly agree, agree, not sure, disagree 
and strongly disagree' on a likert scale would be best suited for teachers of the deaf who needed to show their perspective on the assessment of candidates with profound hearing impairment.

\subsection{Demographic Data of Participants}

\section{Findings}

(a)Teachers (n=50)

Teacher's qualifications $(\mathbf{n}=\mathbf{5 0})$

The results showed that 16 teachers had a Diploma/ Certificate in Special Education and 12 had a Bachelor of Education in Special Needs Education. The other 22 had general education qualifications.

eachers Experience in Deaf Education (n=50)

$92 \%$ had experience of over six years teaching students with hearing impairment and only $8 \%$ comprise the beginners. The $92 \%$ is expected to have gained a lot in the teaching of students with profound hearing impairment.

(b) ZIMSEC Exam Managers ( $\mathrm{n}=10)$

Working Experience

Figure 1: ZIMSEC Managers' Working Experience

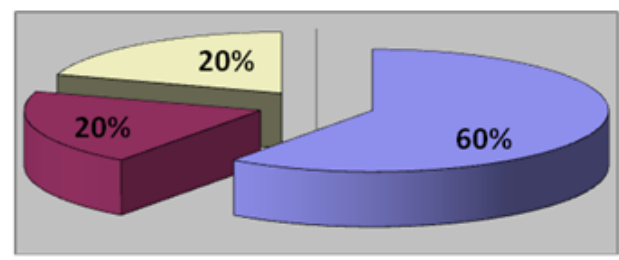

$\square 0-5$ years

$\square 10-15$ years

$\square 16$ years and above

From the figure it can be deduced that a total of 4 managers had experience of over six years working with ZIMSEC in their current portfolio. Six of the participants had experience of maximum five years.

\section{Managers' Professional Qualifications}

Fig 2: ZIMSEC Managers' Qualifications (n=10)

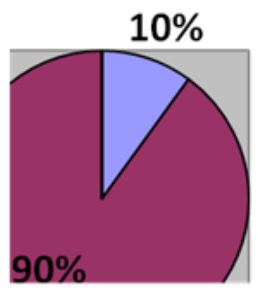

B. Ed...

Other

The figure shows that only one manager had qualifications in special needs education and the rest possess other qualifications.

\subsection{Marking of Examination Scripts for Deaf Candidates}

Respondents were asked different questions regarding the marking of examination scripts of deaf candidates.

Teachers Responses

Fig 3 : Marking of Scripts for the Deaf Candidates

$(\mathbf{n}=\mathbf{5 0})$

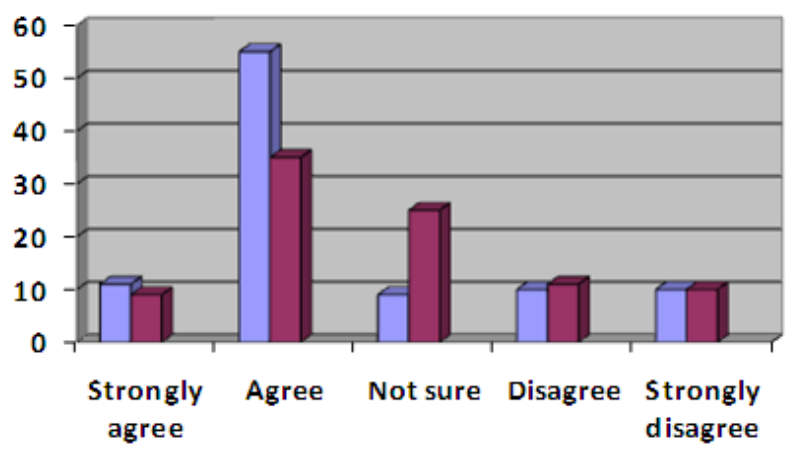


Figure 3 portrays the results from items 16 and 17 which focused on whether teachers of the deaf were involved in marking or not and the errors condoned during marking respectively. Thirty-five agreed, 3 were not sure and 12 disagreed with item 16. In item 17, 14 participants were not sure, 23 agreed and 13 disagreed that the errors listed were condoned.

The following comments were also made by the teachers on the marking of scripts for candidates with profound hearing impairment.

$>$ Markers for the deaf must be teachers for the deaf who are proficient in sign language (40\%).

$>$ Markers should be given training for competence in marking scripts for the candidates with profound hearing impairment $(50 \%)$.

\section{ZIMSEC Managers' Responses}

Table 1: Marking of Scripts for Candidates with Deafness

\begin{tabular}{|l|l|l|l|l|l|l|l|l|l|l|l|l|}
\hline Questionnaire & \multicolumn{2}{l|}{ Strongly Agree } & \multicolumn{2}{l|}{ Agree } & \multicolumn{2}{l|}{ Not Sure } & \multicolumn{2}{l|}{ Disagree } & \multicolumn{2}{l|}{$\begin{array}{l}\text { Strongly } \\
\text { disagree }\end{array}$} & \multicolumn{2}{l|}{ Total } \\
\hline Item & F & $\%$ & F & $\%$ & F & $\%$ & F & $\%$ & F & $\%$ & F & $\%$ \\
\hline 16 & 2 & 20 & 3 & 30 & 4 & 40 & 1 & 10 & 0 & 0 & 10 & 10 \\
\hline 17 & 0 & 0 & 4 & 40 & 3 & 30 & 1 & 10 & 2 & 20 & 10 & 100 \\
\hline
\end{tabular}

The results in table 1 shows that the ZIMSEC managers were themselves not in agreement regarding the involvement of teachers of the deaf in the marking of exam scripts. The majority $(60 \%)$ were either not sure or disagreed.

Table 2: Grading Process

\begin{tabular}{|c|c|c|c|c|c|c|c|c|c|c|c|c|}
\hline Questionnaire & \multicolumn{2}{|c|}{ Strongly Agree } & \multicolumn{2}{|c|}{ Agree } & \multicolumn{2}{|c|}{ Not Sure } & \multicolumn{2}{|c|}{ Disagree } & \multicolumn{2}{|c|}{$\begin{array}{l}\text { Strongly } \\
\text { disagree }\end{array}$} & \multicolumn{2}{|c|}{ Total } \\
\hline Item & $\mathrm{F}$ & $\%$ & $\mathrm{~F}$ & $\%$ & $\mathrm{~F}$ & $\%$ & $\mathrm{~F}$ & $\%$ & $\mathrm{~F}$ & $\%$ & $\mathrm{~F}$ & $\%$ \\
\hline 18 & 0 & 0 & 0 & 0 & 1 & 10 & 4 & 40 & 5 & 50 & 10 & 10 \\
\hline
\end{tabular}

ZIMSEC managers were asked on whether there is a separate grading system for the deaf candidates.

Table 2 shows that all managers agree that candidates with profound hearing impairment are not considered separately during the grading process. ZIMSEC's ranking on the stanine scale (grades 1-9 that appear on the grade seven certificate) bunches all candidates together regardless of their diverse needs and handicapping conditions.

\section{Responses from Focus Group Discussions}

What is your opinion on the way scripts for candidates with deafness are marked? $(\mathbf{n = 5 0})$

The majority of teachers were not aware of how scripts were marked. They however suggested that the pigeon English used by the deaf be condoned in all subjects.

\section{Responses from School Heads Interview}

What is your opinion on the way scripts for candidates with deafness are marked? $(n=4)$

The heads (100\%) believed that teachers of the deaf should mark scripts for the deaf because they understand language of the deaf. They talked highly of the recent development of involving teachers of the deaf in the marking of scripts for candidates with deafness.

\subsubsection{Table 3: Language for Candidates with Deafness}

\begin{tabular}{|c|c|c|c|c|c|c|c|c|c|c|c|c|}
\hline \multirow{2}{*}{$\begin{array}{l}\text { Questionnaire } \\
\text { Item }\end{array}$} & \multicolumn{2}{|c|}{$\begin{array}{l}\text { Strongly } \\
\text { Agree }\end{array}$} & \multicolumn{2}{|c|}{ Agree } & \multicolumn{2}{|c|}{ Not Sure } & \multicolumn{2}{|c|}{ Disagree } & \multicolumn{2}{|c|}{$\begin{array}{l}\text { Strongly } \\
\text { disagree }\end{array}$} & \multicolumn{2}{|c|}{ Total } \\
\hline & $\mathrm{F}$ & $\%$ & $\mathrm{~F}$ & $\%$ & $\mathrm{~F}$ & $\%$ & $\mathrm{~F}$ & $\%$ & $\mathrm{~F}$ & $\%$ & $\mathrm{~F}$ & $\%$ \\
\hline 18 & 0 & 0 & 2 & 4 & 8 & 16 & 12 & 24 & 28 & 56 & 50 & 100 \\
\hline 20 & 0 & 0 & 6 & 12 & 21 & 42 & 10 & 20 & 13 & 26 & 50 & 100 \\
\hline
\end{tabular}

Table 3 shows results from items 18, 19 and 20. Item 18 focused on uniform of sign language. Only 2 participants agreed that sign language was unified, 8 were not sure and the rest disagreed. Item 19 showed 41 participants dismissing assessment of local languages, 8 showed that local languages should be assessed and only one was not sure. In item, 20, twenty-three participants said that there was no government policy on the assessment of candidates with profound hearing impairment, 21 participants were not sure and six said there was policy.

The participants raised issues on languages for candidates with profound hearing impairment laid below

$>$ There is need for teachers of the candidates with deafness to learn and become proficient in sign language $(90 \%)$. 
$>$ There was need to unify sign language and come up with a Zimbabwean sign language that is practiced in schools $(100 \%)$.

\subsection{Assessment Language for Deaf Candidates}

Participants were asked about the friendliness of the assessment language used in examination scripts of deaf candidates.

\section{Responses from Focus Group Discussions for Teachers (FGDs) $(\mathbf{n}=50)$ What is your analysis of assessment instruments developed by ZIMSEC in relation with candidates with deafness?}

The teachers in the FGD raised critical points on the above question. Questioning technique was found to be not user friendly to candidates with deafness. The teachers cited abstract concepts in examination papers as creating difficulty for candidates with profound hearing impairment. The length of both compositions and comprehension was another obstacle that was cited. Language barriers highlighted included proverbs, similes, metaphors related words and synonyms. Higher order questions such as those requiring inferences were also considered to be handicapping.

\section{What challenges of language do candidates with deafness have that impact on examinations taking?}

The FGD cited idioms, words related to sound, local languages, proverbs and related words as barriers to test taking by candidates with profound hearing impairment.

\section{ZIMSEC Managers Responses}

Table 5: Language for Candidates with Deafness $(n=10)$

\begin{tabular}{|c|c|c|c|c|c|c|c|c|c|c|c|c|}
\hline \multirow{2}{*}{$\begin{array}{c}\text { Questionnaire } \\
\text { Item }\end{array}$} & \multicolumn{2}{|c|}{ Strongly Agree } & \multicolumn{2}{|c|}{ Agree } & \multicolumn{2}{|c|}{ Not Sure } & \multicolumn{2}{|c|}{ Disagree } & \multicolumn{2}{|c|}{$\begin{array}{l}\text { Strongly } \\
\text { disagree }\end{array}$} & \multicolumn{2}{|c|}{ Total } \\
\hline & $\mathrm{F}$ & $\%$ & $\mathrm{~F}$ & $\%$ & $\mathrm{~F}$ & $\%$ & $\mathrm{~F}$ & $\%$ & $\mathrm{~F}$ & $\%$ & $\mathrm{~F}$ & $\%$ \\
\hline 18 & 0 & 0 & 0 & 0 & 3 & 30 & 5 & 50 & 2 & 20 & 10 & 10 \\
\hline 19 & 3 & 30 & 0 & 0 & 4 & 40 & 1 & 10 & 0 & 0 & 10 & 100 \\
\hline 20 & 0 & 0 & 0 & 0 & 2 & 20 & 5 & 50 & 3 & 30 & 10 & 100 \\
\hline
\end{tabular}

Table 5 shows results from items ie,19 and 20. Item 18 focused on unification of sign language. Only 2 participants agreed that sign language was unified, 8 were not sure and the rest disagreed.

Item 19 showed 41 participants dismissing assessment of local languages, 8 showed that local languages should be assessed and only one was not sure. In item 20, twenty-three participants said that there was no government policy on the assessment of candidates with profound hearing impairment, 21 participants were not sure and six said there was policy.

\section{Responses from School Heads Interviews $(n=4)$}

What challenges of language do candidates with deafness have that impact on their examinations?

Heads of schools that enroll students with deafness (100\%) reported that the language used for assessment is in itself a barrier to candidates with hearing impairment. The pre-lingual deaf candidates were the most affected observed the head (24\%). The head also indicated that candidates with deafness do not understand written language easily. The head proposed that candidates be tested in the language they understand - sign language.

\section{Discussion}

It was evident from the responses that teachers were aware that scripts for deaf candidates were marked by teachers of the deaf. This development was welcomed and recommendations were made to train such teachers for competence during marking. What was difficult to arrive at was on which errors should be considered minor and condoned during marking. Some teachers were saying that whenever a key word was found in a child's response that should be marked as correct. This contradicted Exam policy, Trinity College of Dublin (2008) who prescribed errors to condone (see chapter 2 p.30). The researcher echoes EcLan Statement Assessment Procedures and BSL, (20-12) who said where grammar and spelling are core competences of a course, a student's work must be marked on the basis of accuracy in the language. The question remains whether candidates with profound hearing impairment would ever pass English language. This seams difficult, yet the Government of Zimbabwe's policy is that no one goes for tertiary level without having passed English is and imposed language on people with deafness and will remain an obstacle to opportunities for candidates with deafness. English language has structures and language rule that are very different from sign language and to say a candidate with deafness should write this examination is to imminent failure for these candidates especially most pre-lingual deaf. 


\section{Recommendations}

The researchers made the recommendations below towards the development of fair, flexible, reliable and valid assessment procedures that measure performance for candidates with profound hearing impairment accurately.

- Zimbabwe School Examinations Council should modify assessment instruments for candidates with profound hearing impairment.

- Zimbabwe School Examinations Council should involve teachers of candidates with profound hearing impairment during test development from the initial stages through item writing workshops so that tests are set with candidates with hearing impairment, not to be treated as an append ache.

- Zimbabwe School Examinations Council must hold workshops on fairness review guidelines with all item writers focusing on the needs of candidates with profound hearing impairment.

- Zimbabwe School Examinations Council must consider alternative formats of presenting question papers to candidates with profound hearing impairment for example use of videos and overhead projectors.

- Zimbabwe School Examinations Council must develop guidelines governing sign language interpreters during interpretation of examinations.

- Zimbabwe School Examinations should establish flexible formats for candidates with profound hearing impairment to be able to present their responses. These formats should include signing on videos and responding in sign language to an amanuensis/ transcriber.

- The Government and stakeholder should establish a sign language authority to unify in language, train teachers of the deaf in sign language, interpretation ethics and license sign language interpreters.

- Zimbabwe School Examinations Council should establish guidelines that are specific to the marking scripts for candidates with profound Hearing Impairment.

- Government should establish and enforce a policy on the assessment of candidates with hearing impairments following the American principle of "No Child Left Behind Act of 2001".

- Curriculum Development Unit should establish a sign language syllabus to allow candidates with hearing impairment to be assessed for proficiency in their primary language instead of proficiency in English and local languages.

[1]. Agbo, F.O. and Mankilik, M. (1999). The Evaluating of the testing Of Practical Skills in SSC Examination $40^{\text {th }}$ Annual Conference Proceedings of Science Teachers Association Nigeria (STAN, 37-40).

[2]. Assessment Guideline Final August (2010). Guidelines for Assessment and Educational Evaluation of Deaf and Hard - of Hearing Children in Indiana. Based on 511 IAC Article 7, 2008

[3]. Castillo, J.J. (2009). Research Population. http://www.expereincent-resources. Com/research-population.html.

[4]. Cole, N.S. and Zieky, M.J. (2001). The New Faces of Fairness. Journal of Educational Measurement 38:4

[5]. Crewswell, J. W. (2003) Research Design: Qualitative, quantitative, and mixed method approaches. Thousand Oaks, CA: Sage Publications.

[6]. DDA Part 4; Examinations and Assessment Good Practice Guide 1999

[7]. Dietel, R.J. Herman, J.L. and Knuth, R. A. (1991). What Does Research Say About Assessment? NCREL. Oak Brook.

[8]. Earl, L. (2003). Assessment as Learning: Using Classroom Assessment to Maximise Student Learning. Thousand Oaks, CA, Corwin Press.

[9]. Educational Testing Service (2009) A Manual for Developing Locally Appropriate Fairness Review Guidelines in Various Country. ETS International Principles for Fairness Review of Assessment . N.J. Princeton, ETS.

[10]. Exam Policy, Trinity College of Dublin, (2008) Notes for examiners- assessment of students in examinations and guidelines for continuous assessment for student learning Difficulties http://www.tcd/disability/docs/Examineguidelines.doc accessed 23 July $\underline{2012}$.

[11]. Nimo, J. (2012). Consider setting separate examinations for hearing -impaired candidates. Ghana News Agency accessed 30 July 2012.

[12]. Guideline for Marker of Deaf Students (2007). The University's Academic Regulations University of Westminster.

[13]. Guidelines for Assessment and Educational Evaluation of Deaf and Hard of-=hearing Children in Indiana. 5111 AC Article 7. $\underline{2008 .}$

[14]. Guidelines Regarding Sign Language Interpreters (2012). http://access.nuim.ie/disability/information-staff/supporting-studentsdisabilities.deaf-or-hard of hearing No. head 2

[15]. Kofitse, A. (2010) Equity in Assessment in Multicultural Society: An Examination of the Basic Education Certificate Examination by West African Examinations Council in Ghana. A Journal of Educational Assessment . Association for Educational Assessment in Africa (AEAA) $27^{\text {th }}$ Annual Conference. P. 295-307.

[16]. Marschark, M. (2003). Cognitive functioning in deaf adults and children. New York: Oxford University Press.

[17]. Martin, D.S. (2001). Multiple -Choice Test Takers. National Task Force on Equity in Testing Deaf Individuals.

[18]. Mounty, J.L. and Martin, D.S. (2005). Assessing Deaf Adults: Critical Issues in Testing and Evaluation. Washington, D.C. Gallaudet University Press.

[19]. Mitchell, R.E. (2002). Large-Scale Academic Achievement Testing of Deaf and Hard-of-Hearing Students: Past, Present and Future. Sen.qi@gallaudet.edu. Accessed 24 September 2012

[20]. Monash University Education Policy Unit, (2003) Assessment of the Deaf. http://wwwaccess.nuim,ie/disability/informationstaff/supporting-students-disabilities.deaf-or-hard of hearing No of head 2.

[21]. Mounty, J.L. (2002). High-Stakes Testing of Deaf and Hard of Hearing Children: Understanding the Problem and Finding Equitable Solutions. Presentation at the Gallaudet University National Conference on High Stakes Testing: Are Deaf and Hard of Hearing Children Left Behind? Washington D.C. 
[22]. NEBOSH Policy and Procedures (2012). Policy and Procedures for Reasonable Adjustment and Special Consideration, Version 7A. Equality and Human Rights Commission. www.equality human rights. Com.

[23]. Okonkwo-Uwandulu, J., Ojo, F.R. and Onoja, G.O. (2012). The Use of Biometric in Public Examinations: Implications for Educational Development in Africa. Journal of Educational Assessment in Africa. P429.

[24]. Pearson Education Policy Report (2003). Accommodations to Improve Instruction and Assessment of Students who are Deaf or hard of Hearing. Pearson Education Inc. accessed 25 July 2012.

[25]. Popham, W.J. (2002). Combating the Fraudulence of Standards- Based Assessment. Presentation at the Large-Scale Assessment Conference of the Council of Chief State School Officers, Palm Desert, CA.QAA Code of Practice-Precept 131999.

[26]. Ravitch, D. (2003). The Language Policy: How Pressure Groups Restrict What Students Learn. New York. Knopf.

[27]. Sedlacek, E. Kim, S.H. (1995). Multicultural Assessment. Eric Product (071): Eric Digests (selected) (073).

[28]. Smith, M.L. (1991) Put to the test: The effects of external testing on teachers. Educational Researchers. 20 (5).

[29]. Stiggins, R.J. (1991). Assessment Literacy. Phil Delta Kappan. 72 (7)

[30]. The American with Disability Act (ADA) 1991 42 U.S. C. 9112101

[31]. The Individual with Disability Education Act 2004 United Nations Convention for human rights of people with disabilities (2006). Development and Human Rights for All. United Nations Enable. http://www.un.org/disabilities/default.asp?id=150 accessed August 2012

[32]. UcLan Statement on Assessment Procedures and British Sign Language. QAA Code of Practice-Precept 13

[33]. Zieky, M.J. (2006). Fairness Reviews in Assessment. In Handbook of Test Development. NJ: Lawrence Erlbaum. 